\title{
A NOSTALGIA DA VIDA EM BREU BRANCO: DESLOCAMENTO COMPULSÓRIO E LOCUS DE SAUDADE
}

\author{
Vitória Mendes (1) $\triangle$ \\ Universidade Federal do Pará \\ Núcleo de Altos Estudos Amazônicos \\ Programa de Pós-Graduação em Desenvolvimento \\ Sustentável do Trópico Úmido I Belém - Pará - Brasil \\ Jorge Mercês (1) $\square$ \\ Universidade Federal do Pará \\ Núcleo de Altos Estudos Amazônicos
}

Programa de Pós-Graduação em Desenvolvimento Sustentável do Trópico Úmido I Belém - Pará - Brasil 
Em 1984, a implantação da Usina Hidrelétrica de Tucuruí no rio Tocantins provocou uma série de transformações socioambientais que incidiram sobre formas de vida que habitam a região atingida pela obra. O lago artificial formado com o barramento do rio inundou uma área de $2.850 \mathrm{~km}^{2}$ e $72 \mathrm{~m}$ de altura a jusante da barragem no período de cheia, entre janeiro e agosto. Até o enchimento do lago, a região inundada era a casa de pessoas que, com a ocorrência do evento, foram deslocadas compulsoriamente e tiveram que refazer suas vidas nos novos lugares onde passaram a morar. Entre esses novos lugares, Breu Branco - ou "Novo Breu", como moradores locais que sofreram o deslocamento compulsório nomeiam o município -, fundado para servir como destino dos moradores do Breu Velho, quando este "foi para o fundo" do lago de Tucuruí, vivencia a experimentação de uma temporalidade nostálgica, marcada tanto por uma sensação de injustiça, em razão da quebra da promessa de melhoria de vida enunciada na implantação da hidrelétrica, quanto pela mimese do "Breu Velho", encenada no habitar contemporâneo ao "Novo Breu". Entre a existência de estruturas de moradia e a sensação de estar verdadeiramente em casa, há uma distância que os moradores tentam encurtar materialmente, por meio de reformas, pinturas, cultivo de plantas e escolhas de objetos de decoração. Este ensaio fotográfico (Figuras 1 a 7) faz parte das pesquisas sobre deslocamento compulsório realizadas pelos autores entre 2016 e 2017. 


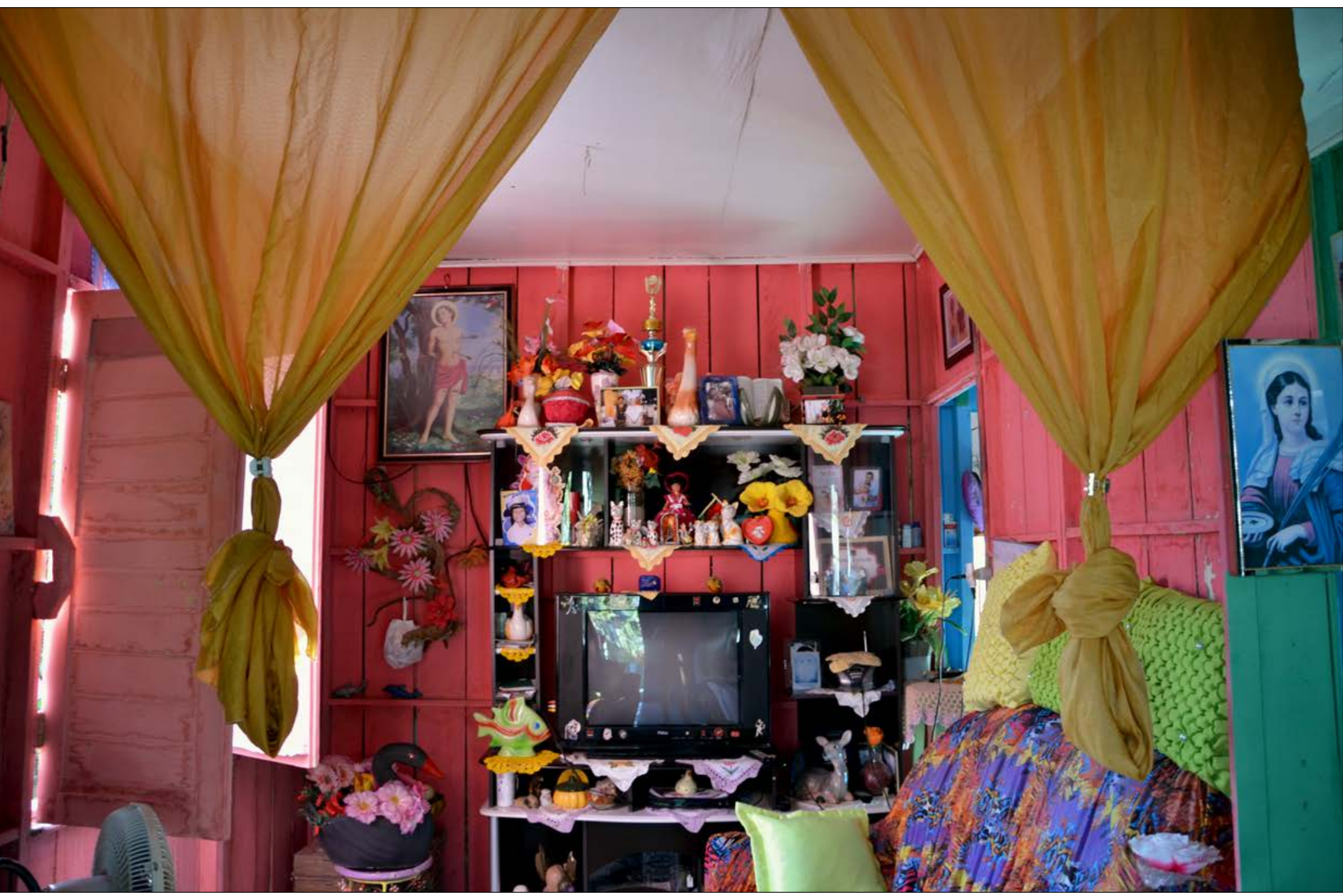

Figura 1 - Ao longo dos anos, Iraídes transformou as saudades do Breu Velho em cuidados e reparos na casa em que vive no Novo Breu. Foto: Vitória Mendes (2016). 


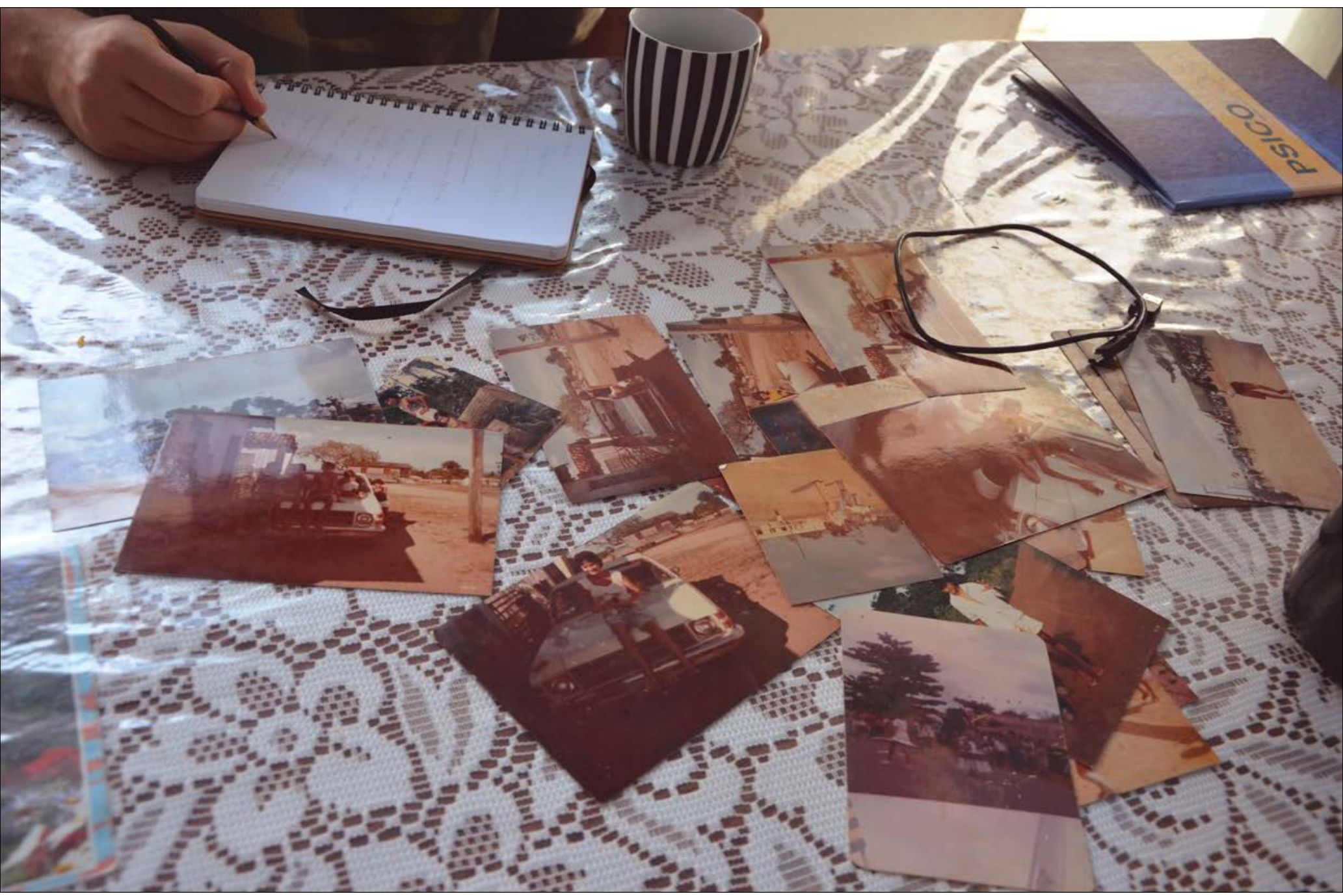

Figura 2 - A saudade do Breu Velho inclina os atingidos a elaborar lugares de memória, como as fotos do arquivo de Osmarina. Foto: Vitória Mendes (2016). 


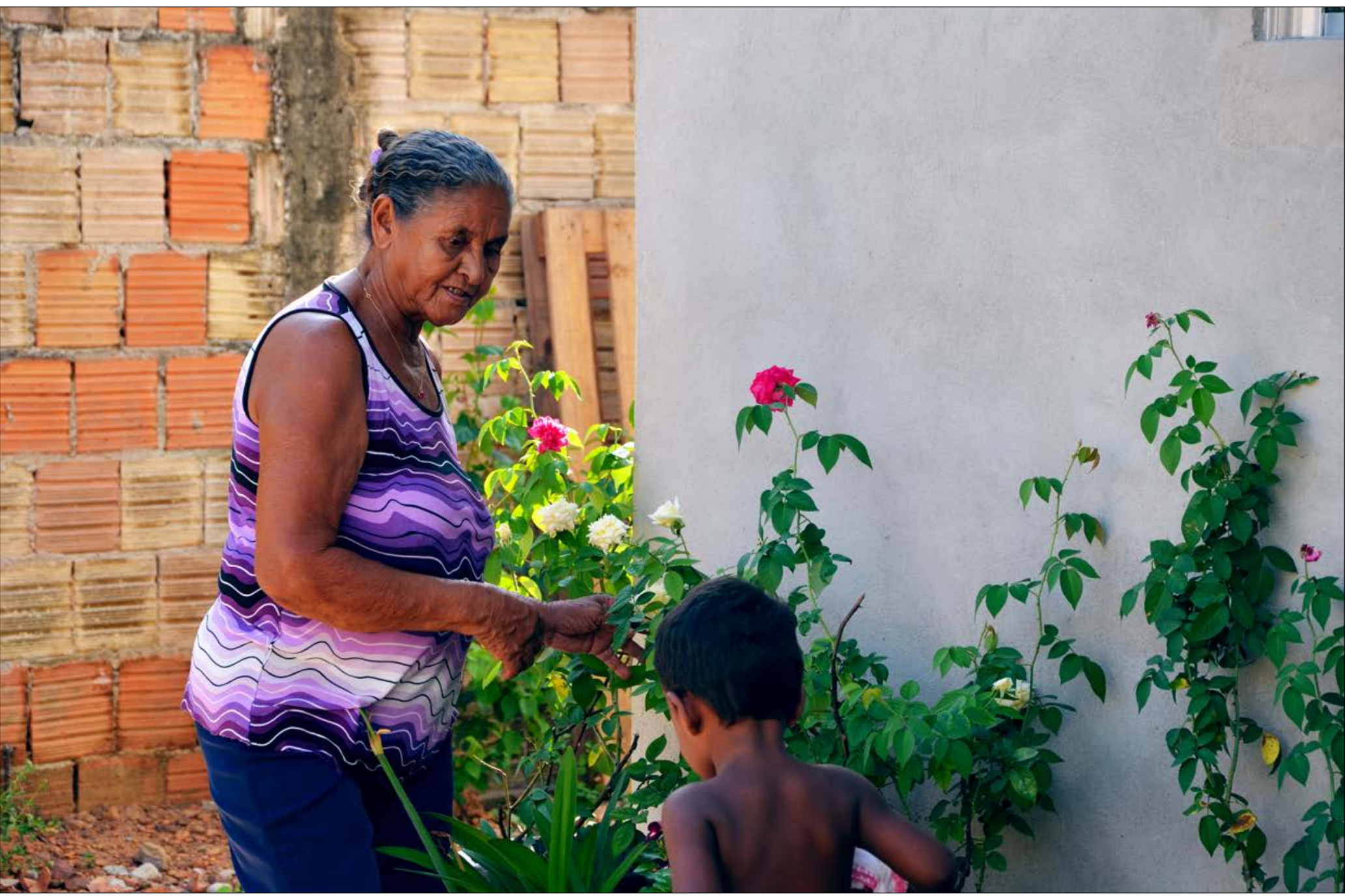

Figura 4 - Em contraste com o concreto de uma casa sempre em construção, as flores de Olgarina enfeitam o lugar. Foto: Vitória Mendes (2016). 


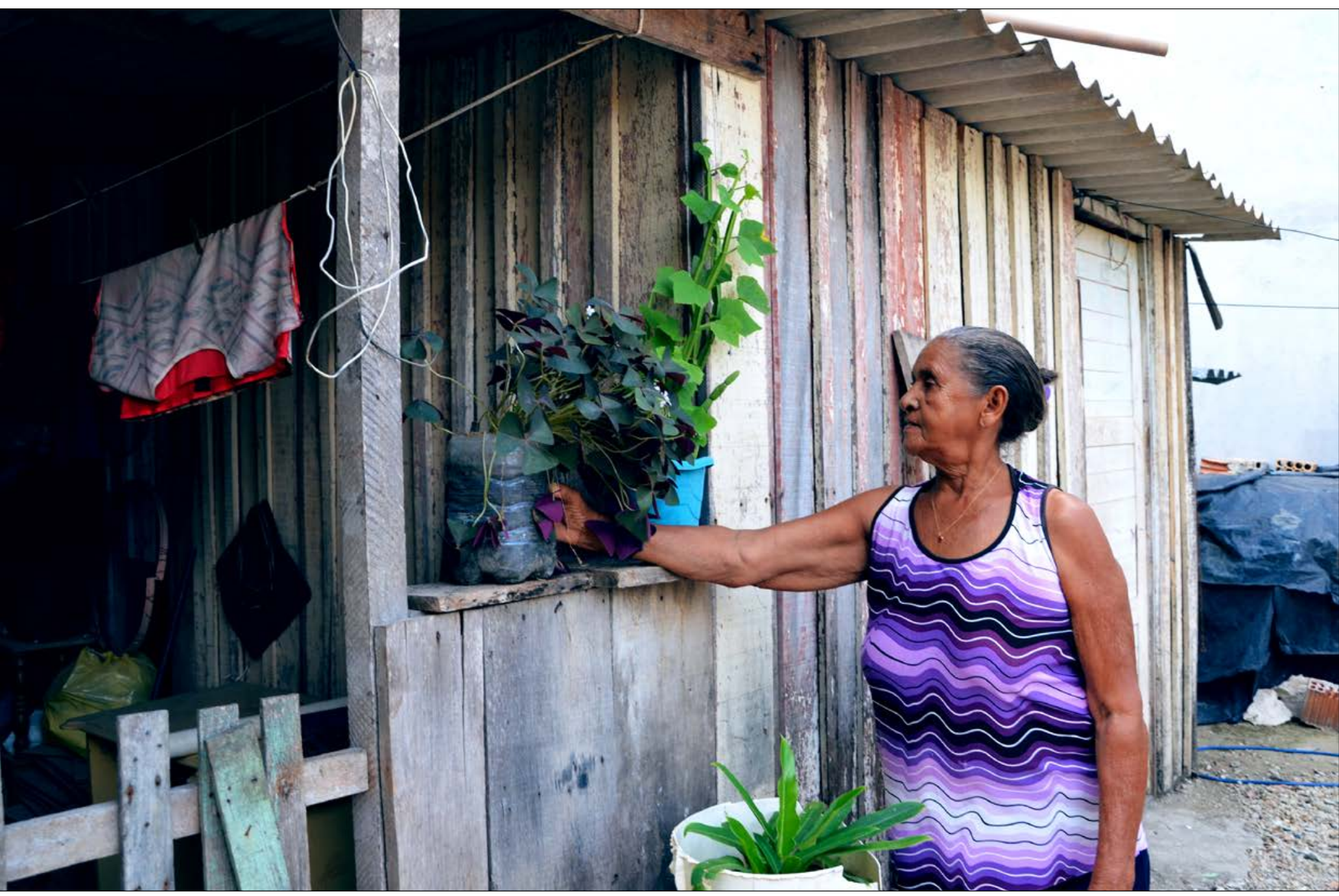

Figura 5 - Cultivos de Olgarina no quintal. Foto: Vitória Mendes (2016). 


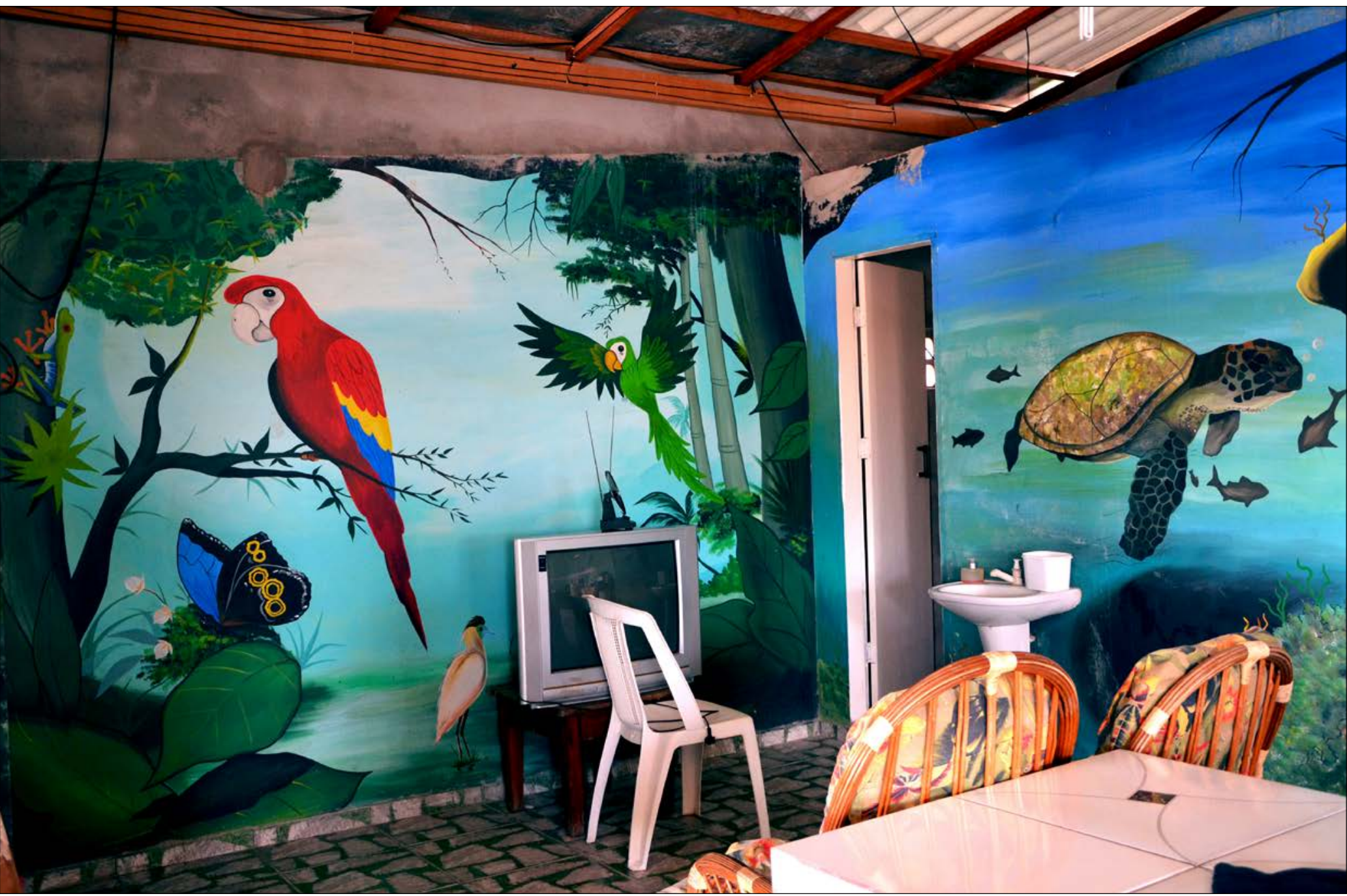

Figura 6 - Entre as tantas reformas que praticam as pessoas deslocadas compulsoriamente desde o barramento do rio Tocantins, o terceiro andar da casa de Osmarina apresenta, nas paredes pintadas, imagens das memórias da sua floresta. Foto: Vitória Mendes (2016). 
